\section{TRAÇOS-MEMÓRIAS NA LITERATURA DAS AMÉRICAS: Margaret Atwood, Linda Hogan, Maryse Condé e Benedicto Monteiro}

\author{
MeMORY-TRACES IN THE LITERATURE OF the AMERICAS: \\ Margaret Atwood, Linda Hogan, Maryse Condé and \\ BENEDICTO MONTEIRO
}

\section{Roland Walter}

Universidade Federal de Pernambuco

Recife, PE, Brasil

\title{
Resumo
}

Neste ensaio, ao relacionar a teoria pós-colonial e a ecocrítica numa abordagem da literatura pan-americana, parte-se da suposição de que a brutalização das pessoas é ligada à brutalização do espaço e essas brutalizações são enraizadas no passado. Alego como hipótese que esta dupla brutalização dos seres humanos e do espaço é interligada e constitui de diversas maneiras o inconsciente político, cultural e ecológico da experiência pan-americana - o fantasma recalcado da violência colonial que volta em resposta à Verleugnung fazendo sentir sua presença tanto no nível da enunciação quanto no da experiência vivida. O objetivo deste ensaio é investigar como a memória literária traduz esta dupla brutalização em textos dos seguintes autores: Margaret Atwood (Canadá); Linda Hogan (EUA); Maryse Condé (Guadalupe) e Benedicto Monteiro (Brasil).

\section{Abstract}

By linking ecological and postcolonial issues as theoretical approach to an analysis of Pan-American literature, this essay's starting point is that the brutalization of people is linked to the brutalization of space - a process rooted in the past. My hypothesis is that these interrelated brutalizations constitute, although in diverse ways, the political, cultural and ecological unconscious of the Pan-American experience: the repressed phantasm of colonial

\section{Résumé}

En utilisant la théorie postcoloniale et écologique dans une analyse de la littérature panaméricaine cet essai part de la supposition que la brutalisation des personnes est liée à la brutalisation de l'espace - un processus enraciné dans le passé. La base de mon argument est l'hypothèse que ces brutalisations constituent, bien que de différentes façons, l'inconscient politique, culturel et écologique de l'expérience panaméricaine: le fan-
Palavras-chave: Memória; inconsciente político, cultural, ecológico; literatura pan-americana; geografia, episteme cultural.

Keywords: Memory; political, cultural, ecological unconscious; Pan-American literature; geography; cultural episteme.

Mots-clés: Mémoire; l'inconscient politique, culturel, écologique; littérature panaméricaine; géographie; épistéme culturelle 
violence that returns as response to a Verleugnung, making its presence felt at the level of enunciation and lived experience. The objective of this essay is to analyze how literary memory translates this double brutalization in select works by Margaret Atwood (Canada), Linda Hogan (USA), Maryse Condé (Guadeloupe) and Benedicto Monteiro (Brazil). tasme réprimé de la violence coloniale que revient en réponse à un Verleugnung et fait sentir sa présence à l'échelon de l'énonciation et de l'expérience vécue. L'essai se propose pour but l'analyse de la traduction de cette double brutalisation par la mémoire littéraire dans des romans sélectionnés de Margaret Atwood (Canada), Linda Hogan (USA), Maryse Condé (Guadeloupe) and Benedicto Monteiro (Brésil).

Se "as memórias irradiam no Traço; habitam-no de uma presença-sem-matéria oferecida à emoção. Suas associaçôes, Traçosmemórias, nem fazem monumentos nem cristalizam uma memória única: são o jogo de memórias entrelaçadas. [...] me fazem com-

* (CHAMOISEAU, Patrick. Écrire en pays dominé. Paris: Gallimard, 1997: 120.)

* (GLISSANT, Édouard. Faulkner, Mississippi. Paris: Gallimard, 1996: 25.) preender-ver-tocar-imaginar o entrelaçamento das histórias tecidas por minha terra"; e se "em nossos países atormentados pela História, onde finalmente as histórias dos povos se juntam, as obras da natureza são os verdadeiros monumentos históricos", * então é necessário, alega-se neste trabalho, relacionar a memória com seu contexto sociocultural e geográfico. ${ }^{1}$ Ao habitar todos os elementos da biota, como os traços-memórias se constroem mediante a "emoção" e imaginação autoral no nível discursivo/narrativo? Quando pedras falam, nuvens se lembram, plantas pensam e animais raciocinam e/ou quando os seres humanos se identificam com as memórias dos seres não humanos em textos literários, ou seja, com relaçâo ao processo mnemônico (inter/trans)biótico, de que tipo de memória se trata?

$\mathrm{Na}$ tentativa de relacionar a teoria pós-colonial e a ecocrítica numa abordagem literária interamericana parte-se da suposição de que a brutalização das pessoas é ligada à brutalização do espaço e essas brutalizaçôes são enraizadas no passado. Alego como hipótese que esta dupla brutalização dos seres humanos e do espaço é interligada e constitui de diversas maneiras o inconsciente político, sociocultural e ecológico da experiência pan-americana - o fantasma recalcado da violência colonial que volta em resposta a

\footnotetext{
${ }^{1}$ As traduções neste ensaio são de minha autoria.
} 
uma Verleugnung (negação) fazendo sentir sua presença tanto no nível da enunciação quanto no da experiência vivida. $\mathrm{O}$ objetivo deste ensaio é investigar como a memória literária traduz esta dupla brutalização em textos dos seguintes autores: Margaret Atwood (Canadá); Linda Hogan (EUA); Maryse Condé (Guadalupe); Benedicto Monteiro (Brasil).

Se nas Américas "a terra é saturada de traumas da conquista”, * a teoria do trauma é um importante artifício para análises mnemônicas do lugar e seus habitantes representados em textos literários. Desde seu avanço na década noventa do século passado, ${ }^{*}$ os insights da teoria do trauma estabeleceram termos como "presença do passado", "perseguição" e "testemunha muda" como respostas tardias a diversos tipos de trauma. A teoria do trauma enfatiza que os problemas e confusóes do presente são resultados de acontecimentos no passado que continuam a ter um impacto precisamente porque seu poder foi negado. Ela argumenta para uma compreensão das narrativas do passado em termos de uma compulsão de falar ligada à supressão do que tem que ser dito, mas parece indizível. No contexto transcultural e multiétnico das Américas com as suas raízes orais, é interessante examinar como a memória oral na escrita dos sobreviventes/descendentes trabalha os diversos traumas em direção à cura; um procedimento narrativo de suma importância (em termos de estilo, estrutura e tema) para a reconstrução de uma história, identidade e psique despedaçada dentre e/ou entre lugares e epistemes culturais.

A tríade geral da teoria de trauma é 'catástrofe', 'luto' e 'perlaboração'. Sigmund Freud* define o luto como o trabalho normal do inconsciente de desprender o ego de um objeto de valor psíquico significante que se perdeu: o processo que exige do ego que encare a realidade da perda. A dor do luto resulta do conflito entre a ligação do ego ao objeto perdido (devido ao encadeamento da libido com este objeto) e a realidade de que o objeto não existe mais. Rituais de luto que atribuem valor simbólico à perda facilitam a percepção da realidade da perda por parte do ego. Considero a teorização de Freud - as ideias sobre o luto individual que traduzo para uma análise do luto cultural - útil para pensar sobre a relação entre os diversos tipos de diasporização, genocídio e outras formas e práticas de desterritorialização (como por exemplo, fluxos migratórios) e a narração destas histórias traumáticas. Neste sentido, a arte (e especialmente a literatura e a crítica literária) deve ser considerada
* (HARRIS, Wilson. Explorations: A Selection of Talks and Articles 1966-1981. Mundelstrap: Dangeroo Press, 1981: 90.)

* (SANTNER, Eric. Stranded Objects: Mourning, Memory, and Film in Postwar Germany. Ithaca: Cornell UP, 1990; FELMAN, Shoshana e LAUB, Dori. Testimony: Crises of Witnessing in Literature, Psychoanalysis, and History. New York: Routledge, 1992; CARUTH, Cathy. Unclaimed Experience: Trauma, Narrative, and History. Baltimore: Johns Hopkins UP, 1996; LACAPRA, Dominik. Representing the Holocaust: History, Theory, Trauma. Ithaca: Cornell UP, 1994.)

* (FREUD, Sigmund. Mourning and Melancholia. In: The Standard Edition of the Complete Psychological Works of Sigmund Freud, vol. 14. London: The Hogarth Press and the Institute of Psycho -Analysis, 1973: 237-58.) 
* (LACAPRA, Dominik. Representing the Holocaust: History, Theory, Trauma. Ithaca: Cornell UP, 1994: 200.)

* (HUYSSEN, Andreas. Diaspora and Nation. In: BARONIAN, Marie-Aude; BESSER, Stephan; JANSEN, Yolande (orgs.). Figures of Displacement in Contemporary Literature, Arts and Politics. New York: Rodopi, 2007: 85.) um dos meios cruciais de perlaborar a perda enquanto problema de ausência - a ausência de totalidade, inteireza e/ou integração cultural mesmo antes da história traumática. Seguindo Freud, entendo perlaborar como processo de lidar com esta perda, atravessá-la trabalhando, ou seja, revelar, examinar, problematizar e assim tornar consciente e reconhecer a implicação numa história traumática cujo impacto é tanto latente quando visivelmente concreto. Não significa a recuperação utópica de uma cultura perdida porque $a$ cultura inteira e original não existe. Significa "a reconstrução de vidas e a elaboração de uma historiografia crítica” pelo processo de "comparação de experiências e [...] reconstrução de contextos mais amplos que ajudam informar e talvez transformar a experiência”.* $\mathrm{O}$ apagamento do ancestral mediante o genocídio, o assassinato, a escravidão (e outras formas de desterritorialização) e a distorção da memória cultural é precisamente o trauma que precisa ser perlaborado para poder reconstruir a episteme cultural.

Se o processo mnemônico é estruturado de maneira performática, então o ato de rememorizar é mais "um ato de recherche do que de recuperação".* Isto significa que a memória é uma função de subjetividade que mediante sua intrínseca natureza móvel enfatiza o sentido de perda (le temp perdu) : a emoção/o sentimento em busca do saber passado. Este saber - já em si um fato imaginado/inventado do evento que realmente aconteceu - transferido da experiência individual vivida para a imaginação coletiva é caracterizado por uma descontinuidade entre o passado vivido e relembrado. Entre o que uma pessoa viveu e como este evento é narrado no decorrer de anos, entre geraçóes, existe uma diferença que faz com que o processo de rememorização seja sempre ligado com a imaginação; ou seja, a memória vivida e a memória imaginada/inventada são entrelaçadas na passagem do tempo.

No contexto da memória traumática vivida e imaginada, Marianne Hirsch utiliza o termo "postmemory" para descrever o tipo de memória daquelas geraçóes subsequentes que não viveram os eventos traumáticos, mas os conhecem somente por meio de "estórias e imagens com as quais cresceram":

A pós-memória é uma forma poderosa de memória precisamente porque a conexão dela com seu objeto ou fonte é mediada não por meio de recordação, mas por projeção, investimento e criação. [...] A pós-memória caracteriza a experiência daqueles [...] cujas próprias estórias tardias são deslocadas pelas histórias das geraçóes 
previas, moldadas por eventos traumáticos que eles podem nem compreender nem recriar.*

Essa pós-memória, segundo Hirsch, "não é uma posição identitária, mas um espaço de remembrance em geral mais disponível mediante atos de rememorização, identificação e projeção cultural e pública e não meramente individual e pessoal”. Como tal, este tipo de memória caracteriza-se pela adoção das "experiências traumáticas - e assim também das memórias - dos outros como as suas, ou mais precisamente, como experiências que se podiam ter tido e pela inscrição destas na sua própria história de vida”. Para Hirsch, a pós-memória abrange relaçôes entre geraçôes do mesmo grupo ou entre grupos etnoculturais e implica uma relação ética com pessoas oprimidas e perseguidas. Hirsch baseia sua argumentação nas ideias de Silverman, que chamou este processo "memória heteropática" e "identificação": por meio de "memórias discursivamente implantadas" a pessoa pode "participar nos desejos, lutas e sofrimentos do outro";* ou seja, mesmo sendo distante pode identificar-se com o outro sem, porém, interiorizá-lo, sem se perder no outro, mas sair de sim em direção aos outros.

O que me interessa nestas ideias de Hirsch e Silverman é se podemos pensar a pós-memória e a memória heteropática no contexto ecológico. Em outras palavras, que tipo de memória abrange o inconsciente ecológico que imbui a relação entre seres humanos e seu ambiente? Se para Jameson* o inconsciente político é a ausente e ao mesmo tempo presente porque desejada revolução cultural que transformaria a hegemonia injusta do sistema político em democracia justa, defino o inconsciente ecológico como ausente e ao mesmo tempo presente porque desejada revoluçâo ecológica que constituiria uma mudança de visão hegemônica e exploradora em relação à biota. ${ }^{2}$ Neste sentido, o processo da rememorização literária abre e constitui um "espaço moral, um espaço no qual ques-

\footnotetext{
${ }^{2}$ Uma mudança de visão e das nossas atitudes em relação ao mundo vegetal e animal - uma ética biótica - é necessariamente baseada numa mudança de imaginação cultural, especialmente dos sistemas internalizados, conjuntos de disposiçóes que geram práticas especificas, o que Bourdieu (BOURDIEU, Pierre. Outline of a Theory of Practice. Cambridge: Cambridge UP, 1977) no processo da analisar o habitus chamou de "inconsciente cultural"; ela é baseada num "compromisso reabitador" que "implica a extensão de uma posição moral e, de vez em quando, até mesmo legal ao mundo não humano" (BUELL, Lawrence. Writing for an Endangered World: Literature, Culture, and Environment in the U.S. and Beyond. London: Belknap Press, 2001: 170).
}

* (HIRSCH, Marianne. Projected Memory: Holocaust Photographs in Personal and Public Fantasy. In: BAL, Mieke; CREWE, Jonathan; SPITZER, Leo (orgs.). Acts of Memory. Cultural Recall in the Present. London: New England UP, 1999: 8-9.)

* (SILVERMAN, Kaja. The Threshold of the Visible World. New York: Routledge, 1996: 185.)

* JAMESON, Fredric. O inconsciente político. A narrativa como ato socialmente simbólico. São Paulo: Ática, 1992.) 
* (TAYLOR, Charles. Sources of the Self: The Making of the Modern Identity. Cambridge: Harvard UP, 1989: 28.)

* (BERGSON, Henri. Matéria e memória. Ensaio sobre a relação do corpo com o espírito. São Paulo: Martins Fontes, 2006.)

* (HALBWACHS, Maurice. La mémoire collective. Paris: Presses Universitaires de France, 1968.)

* (RICOEUR, Paul. La mémoire, l'histoire, l'oubli. Paris: Seuil, 2000.) tôes são levantadas sobre o que é bom ou mau, o que vale a pena fazer ou não, o que faz sentido e tem importância para alguém e o que é trivial e secundário".*

Ao trazer o passado ao presente e neste processo iluminar as sombras esquecidas e os fatos distorcidos dos processos socioculturais de uma sociedade, grupo e tribo, os escritores multiétnicos do continente americano transformam o texto escrito em traço mnemônico de sofrimento, dor e cura como também de alegria e prazer (às vezes imbuído de um sentimento nostálgico e ou amargo da perda de, por exemplo, a infância, membros da família etc.): a esperança reside precisamente no reconhecimento da transitoriedade e na preservação dela na e mediante a escrita. Neste sentido, a escrita mnemônica pan-americana recria a história mediante as imagens contraditórias de remorso e esperança. Em seguida, gostaria de focalizar as obras selecionadas dos escritores pan-americanos para poder melhor ilustrar e elaborar alguns aspectos das ideias acima levantadas.

O romance Surfacing da escritora canadense Margaret Atwood é a história de uma jovem mulher que retorna ao norte de Quebec, à ilha remota onde viveu com seus pais, para investigar o misterioso desaparecimento do seu pai. Durante a viagem que dura aproximadamente uma semana e que ela faz com seu namorado e um casal de amigos, se dá conta de que voltar à casa onde passou sua infância e adolescência significa não somente ir a outro lugar, como também a outros lugares e outros tempos. A espacialização do tempo e a temporalização do espaço mediante a memória condensam diversos lugares e tempos (e como veremos em diante, diversas espécies) numa encruzilhada do presente cheio de fissuras e fusóes entrelaçadas e num contínuo processo de embate entre cidade e campo, civilização e natureza, ser humano e não humano.

A viagem para o interior de Quebec é também uma constante passagem imaginária entre a infância, a adolescência e o presente de uma mulher adulta perseguida pelo trauma de um aborto e do subsequente rompimento com seus pais. Neste sentido, a viagem em busca do pai é ao mesmo tempo uma tentativa de estabelecer contacto com a mãe morta e principalmente consigo mesma: memória individual (no sentido de Henri Bergson), ${ }^{*}$ memória social/coletiva (no sentido de Maurice Halbwachs)* e memória dos proches (no sentido de Paul Ricoeur)* entrelaçadas na tessitura do texto à maneira faulkneriana. Semelhante a William Faulkner (mas com 
frases menos longas e involucradas), Margaret Atwood trabalha o fluir temporal com mudanças de perspectiva e focalização dos personagens em frases e parágrafos sem cortes para grafar os impulsos do inconsciente na consciência. Neste processo, a memória da protagonista traz à superfície da enunciação e do enredo o inconsciente político, sociocultural e ecológico individual e coletivo no sentido étnico-racial, nacional e universal: as diversas formas e práticas de violência entre humanos e entre estes e o resto da biota dentro de uma rede de relaçóes de poder caracterizada por domínio e exploraçáo. Para a protagonista conscientizar-se do fantasma recalcado da violência que volta em resposta a uma Verleugnung e integrá-lo no seu Dasein como memória não traumática significa uma escolha rigorosa:

ser mais cuidadosa com relação às minhas memórias, tenho que ter a certeza que são as minhas e não as memórias de outras pessoas me dizendo o que eu sentia, como agia, o que dizia: se os eventos são falsos também os sentimentos que lembro destes o são, eu começarei inventá-los e náo teria como corrigir tudo isto, aqueles que poderiam ajudar não vivem mais.*

O primeiro passo desta conscientização, portanto, é desconstruir "as memórias fraudulentas como passaportes" que compóem "o álbum falso", esta "casa de papel”* na qual ela tinha vivido até o início desta viagem. Esta desconstrução abrange o inconsciente político, cultural e ecológico: a maneira como a democracia canadense (e por extensáo ocidental) nos anos setenta do século passado era uma hegemonia baseada em oprimir, marginalizar, subalternizar e/ou explorar aqueles outros aparentemente minoritários em nome de um sistema econômico baseado em exploração de matérias primas e consumo desenfreado. Atwood enfatiza os efeitos deste sistema democrático determinado pela economia capitalista nos atos, atitudes e pensamentos do casal amigo e do namorado da protagonista: a completa reificaçáo dos seres humanos. Desde o início da viagem a protagonista descreve a devastação da natureza pelas companhias elétricas (desmatamento, manipulação do nível de água do lago) e pelo turismo (construção de casas, estradas e pontes, caça de animais) em termos alegóricos, ou seja, como espelho da degeneração humana. Num trecho do livro, a protagonista e seus três companheiros de viagem encontram um acampamento de caçadores que depois de terem matado uma garça a penduraram para secar. A imagem persegue a protagonista que se pergunta: "que parte deles é
* (ATWOOD, Margaret. Surfacing. New York: Anchor, 2006: 72.)

*(Ibidem: 149.) 
* (Ibidem: 123.)

* (CURTIN, Deane. Environmental Ethics for a Postcolonial World. Lanham: Rowman \& Littlefield, 2005: 145.)

* (PLUMWOOD, Val. Environmental Culture: The Ecological Crisis of Reason. London: Routledge, 2001: 4.)

*(PLUMWOOD, Val. Decolonizing Relationships with Nature. In: ADAMS, William; MULLIGAN, Martin (orgs.). Decolonizing Nature: Strategies for Conservation in a Post-Colonial Era. London: Earthscan, 2003: 53.)

* (ATWOOD, Margaret. Surfacing. New York: Anchor, 2006: 134.)

* (QUIJANO, Anibal. Colonialidad del poder, cultura y conocimiento en América Latina. Anuario Mariateguiano, v. 9, n. 9, Lima, 1997: 113-120.)

* (ATWOOD, Margaret. Surfacing. New York: Anchor, 2006: 186.)

*(Ibidem: 193.) que a garça representava para que precisassem tanto assassiná-la?”* Aqui, Atwood conota o que o filósofo Deane Curtin* chama de "racismo ambiental", isto é "a conexâo, em teoria e prática, entre raça e ambiente de forma que a opressão de um é ligada e sustenta a opressão de outro". O racismo ambiental é um fenômeno sociológico exemplificado no tratamento ecologicamente discriminatório de povos socialmente marginalizados ou economicamente discriminados. É uma forma extrema do "centrismo hegemônico":* a perspectiva autoprivilegiadora como base do racismo, sexismo, colonialismo e imperialismo; formas e práticas de domínio convocadas historicamente com o objetivo de explorar a natureza e ao mesmo tempo minimizar pretensóes não humanas a uma natureza compartilhada. Neste processo, não se deve esquecer, como Plumwood* assinala, que a definição ocidental da humanidade sempre dependeu e continua depender da presença do náo humano como incivilizado e animalesco. A justificação de processos de invasão, colonização e dominação procedeu desta base antropomórfica e racista que nega e cancela o self independente da natureza, ou, como no caso da garça, que projeta a parte perversa e odiada de si sobre um animal como licença de matá-lo. Uma violência física, psicológica, epistêmica e ecológica resumida na pergunta da protagonista: "Como o mal tomou conta de nós?”*

A protagonista, depois de compreender esta "colonialidad del poder"* que rege todos os aspectos do nosso Dasein e libera o perverso dentro de nós, se distancia dos seus colegas de viagem e mergulha na natureza selvagem - onde as águas de um lago e a selva funcionam como locus amoenus - com o objetivo de reconstruir sua identidade e forma de viver e se relacionar com os outros humanos e não humanos. Esta imersão na natureza - que tem características rituais de passar pelo limen e ter insights antes de voltar à comunidade/sociedade - constitui uma crítica aberta e feroz à civilização ocidental que aliena os seres humanos não somente do seu ambiente, mas de si próprios. Neste sentido, a protagonista quer "parar de estar no espelho [...] para poder ver"* e, como antes mencionado desconstruir as falsas memórias impostas pelos outros para poder reconstruir as suas próprias e desta forma sua subjetividade e identidade dentro de relaçôes de igualdade: encarar o outro do mesmo patamar significa para ela não caçar animais com armas, mas "com as minhas mãos"; significa respeitar o outro, reconhecer o outro dentro e fora de si, identificar com o outro: "Eu encosto-me 
contra uma árvore, sou uma árvore encostada”, ou ainda, algumas linhas em diante, "não sou um animal ou uma árvore, sou a coisa na qual as árvores e os animais movem e crescem, sou um lugar".*

Esta memória biótica - que à diferença da pós-memória não liga diversas geraçóes do mesmo grupo e entre diversos grupos étnicos, mas diversas espécies nas suas experiências vividas, traduzindo um radical compromisso reabitador - imbui a tessitura dos textos da escritora indígena norte-americana Linda Hogan. É por meio desta memória que Angela em Solar Storms se move de uma alienação cultural nutrida pela ideologia branca para uma consciência tribal; que ela aprende que além da história e episteme euro-americana existe um etos e uma cosmovisão tribal que enfatiza conexôes entre os reinos espirtual e material, humano e não humano. Hogan argumenta que "todos nós somos o mesmo mundo dentro de peles diferentes e com inteligências diferentes".* Em outras palavras, para Hogan não existe uma diferença entre o contínuo genocídio de povos indígenas e a destruição da natureza: "o que acontece com pessoas e o que acontece com a natureza é a mesma coisa”.*

A viagem de Angela em Solar Storms de um entre-lugar cultural para uma posição de sujeito dentro da sua tribo constitui um processo de cura nutrido por uma memória biótica que desconstrói os limites que separam os seres humanos dos animais e vegetais, os mortos dos vivos e dos que nascerão. De volta à sua terra natal depois de uma odisseia por orfanatos e escolas da sociedade branca e traumatizada por sua mãe tê-la maltratado e repudiado, Angela imagina ser água correndo em direção à sua fonte. Tendo como cronotopo a região dos Grandes Lagos entre os Estados Unidos e o Canadá nos anos setenta do século XX, onde membros espalhados das tribos Cree e Anishinabe, entre outros, lutaram contra a construção de barragens que ameaçaram inundar suas terras, o romance delineia "a caída" de Angela "num lago",* as águas férteis da narração oral de sua bisavó. Rodeada de água, Angela gradualmente começa a viver:

dentro da água. Não houve separação entre nós. Soube em instantes o que era a água. Era aquilo que tinha sido neve. Passou por florestas antigas, agora desaparecidas. Era a doçura de leite e milho e viajou através de vidas humanas. Era o sangue derramado no chão. Parte deste sangue era dos meus antepassados. [...] Neste momento entendi que eu era uma parte da mesma equação que pássaros e chuva.*
* (Idem.)

* (HOGAN, Linda. Introduction. In: METZGER, Deena; PETERSON, Brenda (orgs.). Intimate Nature: The Bond Between Women and Animals. New York: Ballantine, 1998: xiv.)

* (HOGAN, Linda. Dwellings: A Spiritual History of the Living World. New York: W.W. Norton \& Company, 1995: 89.)

* (HOGAN, Linda. Solar Storms. New York: Simon and Schuster, 1997: 26.)

* (Ibidem: 78-79.) 
Estórias, o poder mnemônico de palavras, desencadeiam os pensamentos e os sonhos de Angela, processo este que a liga com o mundo dos animais, das plantas, das árvores e da água. Este cair na natureza e cultura tribal onde "tudo se une" e "os velhos" podem ser ouvidos "nas cançốes dos lobos"* - um ato de consciência interior por meio do qual a vida e a identidade, o eu e os outros começam a existir dentro de um círculo sagrado - faz com que Angela possa imaginar uma realidade e existência alternativas sem fronteiras:

Talvez as raízes de sonhar se encontram no chão do dia-a-dia, do comum ou no coração ou num lugar sem palavras, mas quando chegam a se unir e crescer sáo como as sementes de hidrogênio e as sementes de oxigênio que juntos criam o oceano, o lago e o gelo. Desta maneira as plantas e eu nos unimos.*

Ao relocar seu self na terra por meio de tropos provenientes da natureza, Angela entra e ativamente recria a historia e cultura da sua tribo. Sua reconstruçáo de identidade e subsequente agir coletivo, com a ajuda de uma natureza falante e pensante, fusiona a energia do povo indígena e a energia da natureza mediante o poder das palavras contra a interferência do intruso branco e sua vivência em desarmonia com a terra e natureza.

Também na obra da escritora guadalupense Maryse Condé a principal característica da memória biótica que surge em Atwood e Hogan - a transfiguração da história e cultura para dentro da geografia (natureza, paisagem, lugar, espaço) - se inscreve numa colonialidade interna e externa que desde o passado continua escrever novos capítulos. Além de ser um meio de suma importância na revelação e resistência à barbárie da civilização ocidental, a memória biótica em Condé é um artifício literário para a recriação dos diversos mitos de fundação de grupos marginalizados, especialmente os dos afrodescendentes.

Em seu romance Crossing the Mangrove, a personagem Xantippe, temido e condenado ao ostracismo pela comunidade de Rivière au Sel, é-nos apresentado, ao longo da trama, pela perspectiva e pelo ponto de vista de diversos personagens, como o idiota da vila, cuja linguagem ninguém entende. No fim do livro, porém, por sua própria voz, ele aparece como o último marron (quilombola) que viveu as diferentes épocas da sociedade guadalupense: a época colonial, as revoltas dos escravos, a abolição, a construção de escolas, o sistema de educação francesa, a fragmentaçáo e aliena- 
ção cultural dos tempos modernos. Em busca de abrigo na selva, Xantippe recorda o passado:

Foi nas raízes das árvores manjack que a poça do meu sangue secou. É que um crime foi cometido aqui mesmo há muito, muito tempo. [...] Sei onde os corpos torturados estão enterrados. Descobri suas covas embaixo do musgo e líquen. [...] cada noite venho aqui para me ajoelhar. Ninguém descobriu este segredo enterrado e esquecido.*

Nesse trecho, Condé trabalha o futuro esquecido do passado no presente: é nos traços invisíveis das ruínas históricas re-imaginadas pela memória que se pode descobrir e compreender fatos que a história oficial oculta. Os traços das histórias que constituem a História são invisíveis, porque não existem monumentos (e, muitas vezes, nem escritos, porque estes foram destruídos) que documentam sua existência. No Caribe, como em muitas outras partes da diáspora negra das Américas, o monumento destas histórias é a memória coletiva e/ou a própria natureza; ou melhor, a força da imaginação mnemônica que erige uma memória impossível porque desejada e inventada dos lugares (e seus elementos constituintes) onde os eventos históricos aconteceram: o vento em Glissant, as nuvens em Guillen, a terra em Morrison, as pedras em Chamoiseau, a água em Walcott. Pelo fato que a ilha é um DOM francês e não tem construída sua própria episteme cultural Condé usa Xantippe para revalorizar o marron como autêntica figura mítica da sociedade guadalupense. ${ }^{3}$ Assim, ao delinear o marron como mito fundador de uma memória coletiva fragmentada e assim enraizá -lo na terra, ela desconstrói a contínua e alienadora busca de mitos na episteme cultural do ex-colonizador francês, esboçando possíveis caminhos de cura, tanto das fissuras e vazios produzidos pela não inclusão das experiências locais nos processos mitopoéticos e discursivos, quanto da concomitante internalização do sistema de valores da cultura dominante. ${ }^{4}$

\footnotetext{
${ }^{3} \mathrm{E}$ o faz em toda sua amplitude ambígua, ou seja, humana: não somente como figura de resistência, mas também, como no seu romance Ségou, em colaboração com o colonizador. Para uma análise crítica do marron, ver CAMPBELL, Mavis C. The Maroons of Jamaica: 1655-1796. A History of Resistance, Collaboration and Betrayal. Granby, Mass.: Bergin and Garvey, 1988 e BILBY, Kenneth B. True -Born Maroons. Gainesville: University Press of Florida, 2005.

${ }^{4}$ Assim como Condé literalmente embute história e cultura no fato natural da paisagem - história e cultura vistas com e como a natureza - Derek Walcott, em Collected Poems 1948-1984. New York: Farrar, Strauss and Giroux, 1986: 213, martela o histórico suicídio em massa dos indígenas Carib para dentro da argila
} 
* (FAULKNER, William. Go Down, Moses. New York: Vintage, 1973: 200.)

* (HOGAN, Linda. Solar Storms. New York: Simon and Schuster, 1997: 86, 170, 203.)
Revelação, denúncia, resistência pela força de palavras imbuídas por uma memória biótica que recupera um mundo de referências. Este mundo de referências (re)territorializa a identidade individual/coletiva dentro de um processo histórico-cultural enraizado num lugar: eis o que une Atwood, Hogan e Condé na sua diferença. Para Isaac McCaslin, o jovem protagonista em "The Bear", um dos capítulos que compóe o livro Go Down, Moses de William Faulkner, muitas coisas são previamente conhecidas, ancoradas no inconsciente. Assim, segundo o narrador, o urso "correu no escutar e pairou nos sonhos" do menino Isaac "desde antes de ele se lembrar".* Ou seja, a memória biótica que liga os humanos com os outros elementos da biota tem ainda outro aspecto: talvez algo que encontre seus traços nos tempos, segundo Angela de Solar Storms, quando o mundo ainda não tinha perdido sua wilderness; quando ainda existia a capacidade dos seres humanos de "fala[r] com a terra"; "quando as pessoas podiam unir-se com uma nuvem e ajudá-la a chover, podiam tornar-se árvores".*

Em A Terceira Margem o autor brasileiro Benedicto Monteiro recria este tipo de memória biótica por meio da voz do caboclo Miguel dos Santos Prazeres. Ao viajar na sua canoa da primeira margem (o vilarejo à beira do rio) por meio da segunda margem (a água dos rios) em direção à terceira margem (a floresta) a voz de Miguel é suplementada (em sua diferença) pela voz de um geógrafo cujo objetivo é estudar os problemas da região para descobrir se é possível construir "A Cidade do Futuro" na Amazônia. Ligado a este projeto científico é seu projeto pessoal de escrever um livro sobre o lendário Miguel dos Santos Prazeres. As viagens dos dois personagens constituem os dois níveis da trama. Ao mesmo tempo separados e ligados pelas duas vozes em diálogo imaginado esses níveis são suplementados por um terceiro nível enunciativo: a voz de um narrador que reflete sobre o fazer literário e problematiza os efeitos bárbaros do processo civilizatório na região.

No livro, portanto, Monteiro mina o lugar como etos mnemônico dentro do espaço nacional por meio de diversas perspecti-

vermelha via linhas caracterizadas por enjambement: "Estou batendo os rostos dos deuses de volta à argila vermelha eles/ saltaram do mattock calcanhar após calcanhar [...]/ ficando sem nome onde os achei -/ na terra deus-criando, deus-devorando!” Neste trecho, como em muitos outros da poesia de Walcott, é a imaginação do poeta que à maneira de Walt Whitman abraça todos em todas as partes: a voz poética em simbiose com as vozes humanas e não humanas da terra. 
vas estruturadas pelas viagens do geógrafo e de Miguel. Neste processo, a territorialidade, vista aqui como a vivência num local, é traduzida pelo agir e pelos pensamentos dos personagens (um diálogo silencioso de monólogos individuais): subjetividades constituídas por meio de experiências que depois se tornam o agente de práticas culturais específicas e sua expressão. Em outras palavras, o significado da territorialidade é transmitido por meio da consciência espacial, suas práticas sociais e relaçôes de poder. Disso resulta que os limites da territorialidade sáo estabelecidos tanto por um mapeamento cartográfico quanto pelo sistema semiótico da linguagem e suas imagens articuladas. ${ }^{5}$

No inicio da sua viagem o geógrafo admite que "existe [...] alguma coisa nos olhos e na fala do povo que eu [...] ainda não consegui decifrar". ${ }^{*}$ No seguinte trecho nota-se que o geógrafo sentese fora do lugar, mas tenta entender, ou melhor, sentir o lugar e seu povo "em toda a complexidade das implicaçóes humanas" em vez de compreendê-lo "apenas como um fato natural":*

Tenho viajado de barco, tentando reconstituir os caminhos de Miguel [...]. Parece que ando sempre na sombra ou nas águas desse ubíquo rio andante. Vou de margem em margem e de porto em porto, a pretexto de uma rota simplesmente geográfica. À medida que me afasto da cidade, que subo ou desço os rios, entro nos lagos e quase me perco nos igarapés, sinto mais de perto que é quase física a sua realidade.*

Miguel, por outro lado, não perde suas raízes locais na rota aquática entre o vilarejo e a floresta:

Já quando me avezei pela canoa gita, desapareceu pra mim essa questão de margens e ribanceiras cortantes. Os furos, os igarapés, os rios e os lagos uniram todos os caminhos andantes. Só eram separadas, de vez em quando, por correntezas e remansos. De repente, o mundo ficou sem ilhas - o senhor sabe - não precisava pontes. A travessia era um caminhar constante.*

A travessia de Miguel é facilitada pela intimidade deste com o ambiente, uma vivência simbiótica caracterizada por transsubjetividade e transtempo: uma mistura entre tempos e seres cujo prin-

\footnotetext{
${ }^{5} \mathrm{O}$ meu argumento se nutre dos pensamentos de SANTOS, Milton. O espaço do cidadão. São Paulo: Edusp, 2007; SOJA, Edward. Postmodern Geografies: The Reassertion of Space in Critical Social Theory. London: Verso, 1989; RAFFESTIN, Claude. Pour une geographie du pouvoir. Paris: Librairies Techniques, 1980; e LEFEBVRE, Henri. La production de l'espace. Paris: Anthropos, 1974.
}

* (MONTEIRO, Benedicto. A Terceira Margem. Belém: CEJUP, 1991: 80.)

* (Ibidem: 17.)

* (Ibidem: 85.)

* (Ibidem: 31.) 
cipal símbolo é o boto - uma criatura andrógina parte peixe, parte homem em constante metamorfose. Ao usar este ente da mitologia amazônica que subverte e transgride qualquer ordem estabelecida e cujo ritual favorecido é a sedução de mulheres e uni-lo com Miguel, Monteiro por meio de uma memória-imaginação biótica recria a episteme cultural desta regiāo amazônica como um constante processo de recriação performativa e híbrida entre todos os elementos; um organismo aberto, vivo e circular:

não era só a intimidade que eu tinha com os peixes. Havia também a maior intimidade que eu tinha com os pensamentos. Era paresque um gozo sereno de liberdade, o senhor entende? Eu era quase um peixe dentro d'água, uma árvore crescendo da terra úmida, ou um pássaro voando livremente [...]. Eu via e ouvia por dentro, de olhos fechados. As cores verdes invadiam toda a minha vista. Era como se eu abrisse os olhos no fundo da água limpa. Nuvens e ondas se misturavam. E folhas, folhas verdes, vertendo cores de todas as cores, reverdeciam na água. E a água e as nuvens na minha mente [...]. Boiei de canga-pé como boto [...] no meio delas [mulheres]. [...] Eu sou um e sou muitos.*

Esta memória biótica, além de recriar o mundo de referên-

* (FOUCAULT, Michel. Nietzsche, Genealogy, History. In: FOUCAULT, Michel; BOUCHARD, Donald F. (orgs.). Language, Counter-Memory, Practice. Ithaca: Cornell UP, 1977: 162.) * (LIPSITZ, George. Time Passages. Collective Memory and American Popular Culture. Minneapolis: University of Minnesota Press, 1990: 213.)

* (MONTEIRO, Benedicto. A Terceira Margem. Belém: CEJUP, 1991: 185.) do caboclo Miguel, serve como contramemória no sentido de Foucault* e Lipsitz* por sua característica oral; memória esta que via discurso $s k a z^{6}$ resiste ao poder ditatorial da palavra escrita determinada pela historiografia e discurso oficiais:

Nunca dei o meu nome por ficar escrito, o senhor sabe. Sempre tinha medo que a minha alma ficasse amarrada nessa porção de letras. Sabe, eu tenho medo que o meu nome escrito me entregasse pra Governo. Mas como o senhor paresque entende das muitas cores e das muitas palavras, é capaz de se embrenhar pelos meus caminhos sempre abertos.*

Se esta contramemória biótica recupera um mundo de referências, uma episteme cultural que dá sentido a uma identidade específica, então o inconsciente político da multivoicedness enunciativo - esta encruzilhada de vozes entre o nível diegético e metadiegético que articulam a diferença e a mesmice cultural - aponta para formas e práticas de (neo)colonialidade que continuam assolar a Amazônia: o projeto de desenvolvimento governamental em cooperação com interesses internacionais que abrange a explora-

${ }^{6}$ Para Bakhtin (BAKHTIN, Mikhail. Problems of Dostoevsky's Poetry. Minneapolis: University of Minnesota Press, 1984: 190-193), skaz indica um discurso oral que vibra no e atua sobre o discurso escrito. 
ção de recursos naturais e o agrobusiness, entre outros, sem levar em consideraçấo os interesses daqueles que vivem na região. Nesta época, a nação nunca tentou ouvir e compreender a região: eis o significado do diálogo silencioso entre as vozes mudas da enunciaçâo narrativa. É neste silêncio falante da contramemória biótica que podemos ler/escutar os ecos da ética do inconsciente político, cultural e ecológico que imbuem a tessitura do texto de Monteiro.

Os textos de Atwood, Hogan, Condé e Monteiro são representações de uma visão integrada de realidade oposta às definiçóes socioculturais do self e do universo baseadas em divisóes que levam à destruição de vida neste planeta. São construtos mnemônicos que encenam diversos tipos de memória - a memória individual, sociocultural, familiar e biótica - com o objetivo de concertar o compromisso rompido entre o mundo humano e não humano, de descolonizar o nosso pensar e agir antropomórfico, de desconstruir limites artificiais e desta forma transformar a nossa maneira de viver, ser e habitar a terra.

Ao revelar uma ligação entre o inconsciente político (a relação intersubjetiva baseada em domínio e subalternização), o inconsciente cultural (a inserção dos seres humanos num sistema hegemônico via doutrinação e ideologia) e o inconsciente ecológico (a exploração e destruição da natureza) os textos conotam o entrelaçamento entre questôes históricas, político-econômicas, culturais e ecológicas. Neste sentido, demonstram que uma transformação ecológica é baseada numa transformação das relaçôes humanas com as espécies não humanas. Ao recuperar a conexão com a natureza podemos explorar possibilidades de renovação social, cultural e psicológica. Uma re-imaginação e reconfiguração do lugar humano na natureza fazem necessária uma interrogaçáo da categoria do humano e como a construção dos seres humanos contra a natureza - com a hierarquização das formas de vida que esta construção implica - foi e continua sendo implícita na exploração capitalista e racista desde o tempo da conquista imperial até hoje em dia.

Nos seus textos Margaret Atwood, Linda Hogan, Maryse Condé e Benedicto Monteiro utilizam uma memória biótica com o objetivo de transfigurar a história e cultura para dentro de um lugar específico. ${ }^{7}$ Como contramemória que recria mitos de fun-

\footnotetext{
${ }^{7}$ Neste sentido, Atwood, Hogan, Condé e Monteiro desconstroem o recente argumento de Ursula Heise (Sense of Place and Sense of Planet: The Environmental Imagination of the Global. Oxford: Oxford UP, 2008) que alega que para um
} 
dação alternativos, esta memória biótica revela e desconstrói as formas e práticas bárbaras da civilização ocidental baseadas em divisão, domínio, exploração e injustiça - uma lógica imperialista - em nome de progresso e consumo desenfreados e suas raízes no passado. Em última análise, suas representações mnemônicas denunciam que sociedades e naçôes que ignoram as ligaçôes trans/interculturais entre seus grupos étnicos e continuam destruir os ambientes que possibilitam a sobrevivência destes grupos não somente violam e, portanto, têm uma concepção errada de sua identidade cultural, mas principalmente não têm legitimidade de existência.

Roland Walter é Professor Associado do Departamento de Letras da UFPE e Pesquisador do CNPq. É doutor em Literatura Comparada pela Johannes Gutenberg Universität, Mainz, Alemanha (1992) e fez pós-doutorado na University of California, Santa Cruz (2000). Roland Walter é autor de três livros - Magical Realism in Contemporary Chicano Fiction (Vervuert, 1993), Narrative Identities: (Inter)Cultural In-Betweenness in the Americas (Peter Lang, 2003) e Afro-América: Diálogos Literários na Diáspora Negra das Américas (Bagaço, 2009) -, editou o e-book "As Américas: Encruzilhadas Glocais" (Ed.UFPE, 2007) e (em co-autoria com Ermelinda Ferreira) o livro Narraçôes da Violência Biótica (Ed.UFPE, 2010) e publicou numerosos artigos e capítulos de livro no Brasil, na Argentina, em Cuba, no Canadá, nos Estados Unidos, na Inglaterra, na Alemanha e na Holanda. E-mail: <walter_roland@hotmail.com>. 